NOTAS

\title{
UN ACERCAMIENTO A LA EDUCACIÓN DEL HOMBRE HUMANO Carlos de la Isla*
}

Recientemente se celebró una reunión singular en Calcuta: Un antiquísimo recinto cobijaba obras de la más antigua civilización de la India de Gandhi. Multitud de indigentes se disputaban la sombra de los muros milenarios. En calles cercanas transitaban turistas ruidosos con sus cámaras de filmación adheridas orgánicamente a sus hombros y a sus ojos.

En el interior, sentados en el suelo, un grupo de profesores de numerosas universidades discutían de manera reposada, pero muy fuerte. Se les oía condenar la guerra, el derroche y la impiedad de la guerra,

\footnotetext{
* Departamento Académico de Estudios Generales, ITAM.
}

sus crímenes y criminales, sus muertos y heridos inocentes.

Hablaban del hambre y del armamento con sus cifras de vergüenza y destrucción. Se preguntaban sobre el posible origen del cretinismo del poder, que coloca a millones de armas junto a billones de hambrientos. Leían cifras de las infinitas diferencias de los ricos más ricos del mundo y de los pobres más pobres, que en cada instante transitan de la agonía a la muerte por falta de pan y de humanidad. Daban datos de países de primer mundo, primeros en abuso, explotación y destrucción del planeta. Condenaban los fundamentalismos de bombas humanas de las guerras santas y del intercambio de petróleo por infelices ciudadanos. 
Después de la estremecedora enumeración de las imágenes dantescas del mundo, que ya parecen normalidades, aquellos singulares académicos formularon dos conclusiones. La primera decía: quien no luche contra las demencias de este mundo será cómplice de sus perversiones; la segunda rezaba: la única revolución con esperanza trasformadora es la revolución del pensamiento.

Tenía razón Heidegger cuando afirmaba: pensar es lo único que puede salvar al mundo. Aunque esto parece un imposible si hemos de creer lo que dijo Saramago cuando recibió el premio Nobel: "El más grave problema del mundo es que nos aproximamos al pensamiento cero." Del pensamiento único avanzamos velozmente al pensamiento cero. Parece imposible que un pensamiento desfalleciente pueda salvar al mundo. Sin embargo, como dice Galeano: "ayuda lo imposible a que lo posible se abra paso [...] nos salva de la maldición del fatalismo y de la peste de la desesperanza. ¿No es ésta, al fin y al cabo, la gran paradoja del viaje humano en el mundo? Navega el navegante, aunque sepa que nunca alcanzará las estrellas que lo guían".

Plantear la educación necesaria, transformadora que haga posible la revolución del pensamiento resulta una construcción de lo imposible, pero hay que hacerlo, porque ayudará a que lo posible se abra paso. Esta auténtica educación parte de una percepción radicalmente distinta de su sujeto y de sus fines. Se propone pensar y propiciar los medios para la afirmación y crecimiento de personas. Sé que esto suena escandaloso, pero pienso que tiene sentido y justificación porque en el mundo contemporáneo la gran mayoría de escuelas y universidades están dedicadas frenéticamente a lucrar en el inmenso mercado de los títulos y de las profesiones. Escuelas y universidades se han convertido en maquiladoras que maquilan mercancías humanas de acuerdo con las especificaciones de los compradores, quienes definen conocimientos, ideas, destrezas y las invaluables virtudes de fidelidad, devoción, entrega y amor a la empresa-madre, y hasta los modos y modales del prototipo arrollador para el éxito económico. Otras transnacionales de la educación cotizan a la alza en la bolsa de valores, porque han aumentado y abaratado la abundantísima y muy lucrativa producción robotizada de funcionarios que funcionan como han sido producidos: en serie, sin resistencia y con técnicas inequívocas e inalterables.

A riesgo de ser juzgado como viejo de tendencias regresivas $\mathrm{y}$ anclado en eras utópicas ideales, debo decir que me resulta intolerable 
$\mathrm{y}$ vergonzoso que universidades y universitarios dignos no protesten masiva y enérgicamente en contra de estos mercaderes, tratantes de productos humanos (alumnos y profesores) en los que sólo aprecian su valor de uso como fundamento de su valor de cambio.

El movimiento estudiantil universitario de 1968 hizo oír en el mundo, a veces por la fuerza, aquel hermoso grito de protesta: "Nos negamos a ser tratados como mercancías, exigimos ser tratados como personas." Ese grito, que yo llamo de la dignidad universitaria, costó la vida de muchos, de muchísimos estudiantes y jóvenes maestros, pero ciertamente cambió la historia de dominación mercantil, aunque duró poco tiempo la conciencia de libertad, de justicia y de respeto a la dignidad de los universitarios. Pronto el sistema apretó sus engranajes de represión, de marginación y de sometimiento contra aquellos que osaron rebelarse en contra de las órdenes y leyes del gran soberano gobierno-mercado.

Ahora casi todas las universidades del mundo funcionan sin cuestionamientos ni rebeldías. Se diría que han tomado en serio sus labores de docencia, de callada investigación y de servicio a la sociedad. La verdad, sin embargo, es que en vez de defender el coto sagrado de la razón, de la autonomía y de la libertad, se han entregado a las seducciones del lucro y de las ofertas publicitarias. Los idealismos y las utopías han sido cruelmente golpeados, como el homo sapiens ha sido abofeteado por el obeso y obsceno homo aeconomicus.

En la educación transformadora se trata, ante todo, de reivindicar la dignidad de la persona que ha sido tan ultrajada: los estudiantes, nuestros estudiantes, deben ser tratados como los invitados de honor al misterio de la vida, grandeza incomparable. Esta apreciación define todo lo demás. De aquí surge el respeto y admiración por ese ser que ya posee potencialidades infinitas, que está llamado a ser de un tamaño impredecible. Cada estudiante puede ser un gigante humano que podría modificar la calidad de la sociedad, del sentido de la vida, de la política, de la escuela. Sí, hay que repetirlo muchas veces: cada ser humano ya posee toda la riqueza y posibilidad de grandeza y genialidad. Sólo necesita, en primer lugar, no ser estorbado, impedido, programado, degradado o vendido; y para su crecimiento sólo pide alimento de verdad, libertad y un campo para desarrollar su fuerza creadora. Aceptadas estas premisas sobre el sujeto excelente de la educación, los medios y caminos serán 
adecuados para propiciar la gestación del hombre humano.

Esencial cualidad en esta educación es el cultivo de la pasión. Me refiero al impulso vibrante, a la energía vital, a la voluntad arriesgada, a la determinación inquebrantable. Me refiero a la pasión en que Hegel pensaba cuando decía: "nada grande se ha hecho en este mundo sin pasión"; es la pasión de la que habla Castoriadis cuando afirma que la revolución por la democracia ya no es posible, porque ésta requiere pasión por la libertad, por la igualdad, pasión por la justicia y por la tolerancia. Y ahora la energía del demos está invertida en aprobar sin molestias las asignaturas del hedonismo en la escuela del gozoso placer sin estridencias.

Se necesita la pasión que se propone lo que para el mundo parece imposible con la energía que desborda las medidas del mundo de medidas. Pasión por ideales aun inalcanzables; por la verdad que desprecia las mentiras del mundo de mentiras; pasión por la justicia que no soporta el uso de personas convertidas en ganancias; pasión para condenar la sociedad que aprecia más las cosas muertas que las dolencias vivas; pasión para combatir la demencia del amontonamiento del poder sin rostro que ha sobrepuesto esclavitudes, iniquidades y aniquilación de los encantos de la vida humana; pasión por las alturas y grandezas para despreciar las mediocridades miserables. Sin esta pasión, como esencia educativa, a nada de lo grande que requiere el mundo se podrá aspirar. Eliminada esta pasión del proceso educativo todo terminará en hombres de cabezas uniformes, de pensamientos cortados a la medida, valiosos y funcionales para una sociedad desabrida, de la política de comedia y de caricatura llagada, de la economía que sigue demostrando sus verdades numéricas en el pizarrón de las desigualdades mortales, en una sociedad aburrida que consume la belleza de los días en el juego de los gozos y placeres de las ofertas, demandas y utilidades. Sin esta pasión, la educación no vale la pena de ser vivida, no vale la pena ni de ser pensada. Para la educación oficial cuadrada, tibia y chata es mejor aplicar la tesis de Ivan Illich: "Hay que desescolarizar la sociedad."

Sin embargo, con esta pasión todo cambia: las dimensiones, las perspectivas, las actitudes, las aspiraciones. La visión alcanza muy alto, más alto, más lejos. Esta visión puede penetrar el futuro desde las cumbres del presente; divisa con precisión las amenazas borrascosas, pero también los caminos seguros; iluminada por el pasado aprende a no hundirse en los pantanos sucios de las armas, de 
los odios, de las muertes; esta visión abarca al mundo entero; sin la miopía pueblerina contempla al mundo entero como hombre del mundo entero. Sólo con esta visión del mundo se puede construir una pieza firme del mundo.

Esta mirada no es la de la globalización que sólo abarca intereses económicos, intervencionistas, civilizadores de los imperialismos abusivos y destructivos. La esencia de esta visión, movida por esta pasión construirá la utopía de la sociedad del hombre humano; sociedad distante de la actual como alejados están el infinito valor de la persona original, creadora, ilimitada del molde vacío y empobrecido, que produce y reproduce lo común, lo normal, lo bien visto para fabricar los disfraces de las marionetas domingueras manejadas por los clubes, consorcios y grupos de poder que apestan.

Otra cualidad indispensable de la educación del hombre humano es la firme aceptación y apasionada defensa de las verdades y bienes que hacen a los hombres grandes. Sí existe la dignidad, el bien inmenso de lo que somos; sí es indecible, pero enorme el bien de la libertad; sí existe infinita diferencia entre el bien que plenifica y el mal que mutila; sí es posible conocer buena parte de lo que es como es, y a esta cercanía e identificación del intelecto y la cosa la llamamos verdad y sí es posible, aunque difícil.

¿A qué viene este bloque de obviedades? Se dirige a denunciar y combatir a los grandes pervertidores que atacan a la razón y exaltan el instinto, a los que culpan a la razón de todos los males más graves del mundo cuando éstos han sido por agresiones a la razón. Es una obligación denunciar y reprobar a aquellos que niegan la existencia de la moral o la hacen consistir en lo que a cada quien le dicta su conciencia.

Hace tiempo escuchaba a un filósofo del derecho, internacionalmente conocido y alabado, que ha sido juez. Afirmaba que el juez debe juzgar y que cuando no encuentra argumentos en el Derecho tiene que constituirse en legislador o acudir a verdades morales; "aunque-dijo textualmente- yo no creo que haya verdades morales". Pero, señor juez, ¿qué son la justicia y la injusticia, el bien y el mal, la verdad o la mentira que ustedes juzgan y sancionan? ¿Todo debe estar contenido y expresado en esa ley positiva producida por los dictadores, los führers, los duces o en el mejor de los casos por legisladores que defienden 'legalmente' el poder de los grupos de poder? ¿Se basan ustedes, señor juez, en esas leyes que justifican procesos inmorales, como se deduce de la declaración del senador que dijo: "Se debe recono- 
cer que el proceso fue legal, aunque inmoral"?

Los grandes enemigos de la educación del hombre humano son los que desprecian a la persona cuando desprecian su razón y predican el agotamiento y los daños de la razón enferma. Grandes enemigos los que exaltan el relativismo intelectual y ético y todo lo reducen al sujeto que quiere, juzga y decide. Son también peligrosos enemigos los que, por defender una falsa autonomía, que quiere ser soberanía absoluta, de hecho se convierten en propagadores de la arbitrariedad, de la obscuridad, de la anarquía y de la lucha de todos contra todos. Son los que gritan que no existen bienes reales ni, por tanto, verdades morales, que todos son construcciones subjetivas, porque lo que dice el sujeto se convierte en objeto.

¿Por qué culpar entonces a los tiranos si tienen su derecho positivo y no existen certezas morales? ¿Por qué condenar a los fabricantes de guerras asesinas si piensan que hacen lo perfecto, porque Dios no sólo está a su lado, sino de su lado? ¿Cómo demostrarles que son asesinos, si no hay leyes ni certezas morales que los condenen? ¿Por qué censurar a los traficantes de esclavos de la necesidad, a los torturadores, a los violadores, a los políticos infames, a los comerciantes de escuelas, a los vendedores de soberanía nacional... si todos tienen su conciencia justificadora y no existen, una vez más, leyes ni verdades morales que los juzguen y que los condenen? Este cáncer del relativismo ético e intelectual debe ser amputado con despiadada cirugía para cultivar con fecundidad los grandes bienes, los grandes amores, los grandes ideales que son el móvil y que dan sentido a la existencia.

Ha sido enfermiza la actitud de universidades que se confiesan imparciales, indiferentes, neutrales en relación a ideas y valores. No advierten que caen en un absurdo pedagógico; porque no hay neutralidad posible. La pretendida neutralidad entraña ya una muy definida actitud de escepticismo, agnosticismo e indiferentismo. Una cosa es la pluralidad benéfica y otra muy distinta la neutralidad cobarde. Es repugnante la Universidad obsesionada sólo por sus ganancias. Allí no existen ni indiferencia ni neutralidad.

La educación del hombre humano deber ser apasionada defensora de los bienes y verdades que construyen personalidades y sociedades con humanidad (la reiteración es consciente). Es indispensable exaltar y defender, al menos con la misma agresividad con que se les ataca, la vida, la dignidad, la verdad, la 
libertad, la justicia, la tolerancia... en pocas palabras, la excelencia de todo lo verdaderamente humano y no inhumano. Por supuesto, manteniendo siempre la apertura al cuestionamiento que protege del fanatismo.

La educación necesaria para desatar la revolución del pensamiento no puede ser otra cosa que la educación auténtica del hombre humano que, como se ha dicho y es mejor repetirlo, parte del altísimo concepto de lo que el hombre es y de sus inmensas potencias transformadoras, en oposición a su degradación mercantil; educación que genera la pasión creadora que empuja a ser grande y a sacudir a la sociedad en oposición a la tibia mediocridad acomodaticia empantanada en datos, notas y títulos para la vendimia de productos universitarios; educación de la visión que cubre el mundo y los tiempos del mundo. Y luego, el alimento, fortalecimiento, ejercicio de las poderosísimas potencias y facultades humanas: inteligencia, voluntad, memoria, imaginación, sensibilidad estética... Porque es necesario reivindicar también, sacudidas por el asombro, esas maravillosas facultades tantas veces despreciadas y desperdiciadas en los desechos de lo despreciable.

La inteligencia es una potencia que puede conocer todas las cosas, puede leer su interioridad y lo que es más importante, su propia inte- rioridad. No sólo lee, sino que se lee, y esa conciencia de su lectura es el primer acto específicamente humano. Cuando la inteligencia lee bien y pronuncia bien su lectura, es decir, cuando dice qué es lo que la cosa es, entonces se desprende el fruto natural de la inteligencia, que es la verdad. A este acto se le llama concepto, porque es lo concebido por el entendimiento.

El quehacer de la inteligencia consiste en ser buena lectora y concebir buenos conceptos. Cuando lee adecuadamente no engaña. La inteligencia es luz, da luz y es la mejor consejera del hombre humano. (Por cierto la Universidad deber ser la lúcida inteligencia de los pueblos.)

La inteligencia tiene apetito de saber, y como el ámbito de lo que pueda saber es infinito, el apetito de la inteligencia es infinito. El conocimiento verdadero es el alimento de la inteligencia. Una inteligencia bien alimentada crece. Y su mayor crecimiento se da cuando se alimenta, como dice Platón, en la inmensa pradera interior de la verdad. Como existe el derecho al alimento para saciar el hambre, existe también el alimento para saciar el apetito de saber. La mente humana no puede nutrirse con bellotas. La mente requiere alimento mental. Si estás lleno de llanuras no concebirás montañas. 
Si estás pleno de vacío nunca tendrás plenitudes.

Sin embargo, la inteligencia que lee y pronuncia la esencia de lo bueno, de lo bello, de lo justo no hace al hombre bueno, virtuoso y justo. De hecho, el hombre puede conocer lo recto y ser torcido, puede conocer el bien y ser perverso. Han existido innumerables hombres de inteligencia brillante y de conductas malvadas, porque la inteligencia no se comporta como dictadora implacable, sino que es siempre respetuosa de la voluntad libre. La inteligencia sólo es inflexible cuando lee la evidencia y la expresa incorruptiblemente, aunque no sea obedecida.

La calidad moral de una persona no se da por sus conocimientos sino por sus actos; y los actos del hombre humano son construcciones, en última instancia, de su voluntad libre. La voluntad quiere querer, quiere elegir entre bienes, tiene urgencia de ser libre. La voluntad se hace fuerte por sus elecciones. Si no se ejercita, la voluntad se debilita y desmaya. La esclavitud es el desmayo permanente de la voluntad, es la muerte del ser humano en cuanto humano. Gran vergüenza de nuestra sociedad son los millones de esclavos que mueren sin saber lo que es la libertad.

El peor enemigo de la libertad es la inevitabilidad. La vida humana que contiene el drama misterioso de la responsabilidad de proyectarse, es la continua lucha entre libertad e inevitabilidad, en expresión de Tolstói. El hombre se degrada cuando agranda el campo de la inevitabilidad y encoge su libertad por hábitos que esclavizan.

La inteligencia y la voluntad son las potencias constructoras de humanidad. La inteligencia, como se ha dicho, ilumina las obscuridades, analiza, juzga, muestra lo conveniente, lo justo, lo verdadero. La inteligencia diseña el proyecto de acuerdo a las aspiraciones. Pero es la voluntad la que decide, la que ordena, quiere y ama. Los hombres y mujeres de gran tamaño, que han hundido su huella en la historia han sido hombres y mujeres de firme y poderosa voluntad, de vigoroso carácter.

La voluntad sería mero apetito salvaje o impulso maquinal si no fuera por la libertad que la reviste de dignidad y responsabilidad. Por la libertad el hombre es el único ser en la naturaleza que nace con la tarea de hacerse; por eso la actividad más importante para cada hombre es cumplir con pasión 'el oficio de ser hombre'. Nadie puede encomendar a otro la responsabilidad de inventar y construir su proyecto de vida.

La libertad es la cualidad excelente, sin embargo el hombre no nace con su carga de libertad al hombro. ("La libertad es ese algo maravilloso 
que se hace día a día", decía Octavio Paz.) El inmenso problema de la libertad radica en la posibilidad de ejercerla.

$\mathrm{Si}$ es esclavo el que no tiene elecciones posibles, el que vive en el sometimiento, el que es más hijo de sus circunstancias que de sus padres, el que tiene derecho a ser libre sólo por decreto constitucional, entonces resulta ofensivamente falso que se haya acabado la esclavitud. Por el contrario, hay que afirmar que nunca han existido tantos millones de esclavos como ahora. Sin duda la mayor agresión artera a la sociedad contemporánea ha sido la globalización de la esclavitud; aunque también son esclavos los que están sometidos por la patología de la dominación política, de la obsesión económica y de la imposición social. No hay desideratum más urgente para la humanidad del hombre humano que procurarle opciones de elección, opciones de libertad.

La sensibilidad estética ansía la belleza. El gozo estético de la contemplación de lo bello es un placer superior, sólo comparable con el gozo del intelecto cuando disfruta la verdad o con el de la voluntad cuando se propone un gran bien y lo alcanza. (El gozo del amor.) ¡Qué diferente es el recorrido de la educación cuando camina sus caminos con el gozo de la verdad, el gozo del amor, el gozo de la belleza!

Es afortunado y grande el educador que entiende y practica así la educación del hombre humano.

\section{La educación del hombre humano y los Estudios Generales}

Los Estudios Generales son una gran oportunidad, un gran medio para la educación del hombre humano. Allí está la fértil y fecunda llanura de cosmovisiones para que la inteligencia se alimente, para que se ejercite en la admiración, contemplación y valoración de las extraordinarias construcciones de ideas de la vida para la vida.

Ideas de la civilización occidental, todas ellas sembradas en su tiempo. Oportunidad para examinar la correlación del pensamiento con ese tiempo al que los hombres tanto se parecen. Excelentes creaciones que nos dejaron como proyecciones vivas con personalidad inmejorable para realizar la tarea de engarzar las vidas, sus historias y sus lecciones. Magníficas expresiones de lo que significa la existencia rodeada de quehaceres y deberes. Es el gran ejercicio para que la mente conozca, compare, se adhiera o rechace, y para que el estudiante y maestro se 
nutran y puedan llegar a construir su cosmovisión propia, es decir el alma de su existencia.

¿Qué bueno que los cursos de Ideas e instituciones politicas y sociales no son meras historias del pensamiento; qué bueno que el objetivo de estos cursos no es un mero ejercicio de la memoria, porque la memoria guarda, retiene, pero no convierte en vida! En los cursos de Ideas se pone en juego el centro mismo de la existencia que mueve la intimidad del ser personal. Aquí aparece también la selección de bienes para elegir y generar los propios fines que mueven y dan tamaño a la persona que se va perfilando en personalidad.

Estos cursos, tomándolos en vivo, generan espontáneamente la pasión por la verdad, por la justicia, por la grandeza, diferencia primordial en la educación del hombre humano. Aquí pueden descubrirse también las perspectivas ilimitadas de la visión que modifica el mundo y que percibe o descubre los caminos de transformación.

En esa reflexión crítica amplísima se hallan innumerables elementos y razones para gestar las propias ideas y convicciones que construyan la defensa contra los valores dominantes que pretenden abarcarlo todo, someterlo todo. Es el inmenso recurso de la mismidad frente a la alteridad; es la oportunidad de la posible gran elección, que terminará en el señorío del amo o en la esclavitud del esclavo.

Allí también, en los Estudios Generales, están los más graves problemas de nuestra civilización para transitar continuamente de las ideas a la vida y a los problemas de la vida. Desde las ideas los problemas adquieren otras dimensiones: se conocen mejor, se aprecian mejor sus angustias, urgencias y obscuridades. Excelente propósito en un mundo de sombras y mentiras en el que se imponen dicciones, visiones e interpretaciones de todo lo que sucede para imponerle dirección, fin y conveniencia.

Desde las ideas se pueden y se deben hacer mejor los estudios de separación de partes para integrar $\mathrm{y}$ entender mejor el todo; se pueden valorar, juzgar y calificar los tremendos golpes que destrozan la parte más frágil, sensible y agobiada de la humanidad y del mundo mismo. Y desde allí la tarea, la gran tarea de encender todas las luces que iluminen soluciones donde parecen imposibles, por el peso y poder de los dominadores. De aquí, de esta reflexión y por la fuerza irresistible de hechos y perversiones, debe brotar, mejor dicho, explotar el compromiso de invertir alma, inteligencia y 
voluntad en la solución de lo reprobable, condenable, maldecible.

La Historia sociopolitica de México es, en el conjunto, una materia muy especial, porque emplea las ideas estudiadas, porque aporta sus propias ideas, y éstas son el mejor instrumento para el análisis crítico de los hechos históricos, que también son problemas. Y siempre auxiliados por la maestra Historia, que por menospreciarla y desplazarla de la memoria, México ha sufrido terribles destrucciones, agresiones y ofensas.

La intención de ordenar cinco materias de Problemas e Ideas antes de los cursos sobre México es evidente. Clara preparación, en lo que ya en sí es fin importante, para el estudio más fuerte, más urgente sobre el prójimo, lo próximo, nosotros todos.

En ese sentido debería considerarse Problemas de la realidad mexicana contemporánea la materia, el curso más importante de todas las carreras, si hemos de tomar en serio el gran objetivo institucional de colaborar en la construcción de una sociedad más libre, más justa, más humana.

Los Estudios Generales pueden ser, ciertamente, un gran medio para la educación del hombre humano, pero también pueden convertirse en un material inerte, de tareas irrele- vantes, de burocrática evaluación. La actitud del maestro principalmente hará la gran diferencia.

\section{La evaluación}

En el difícil y complejo tema de la evaluación es conveniente partir de algunas certezas y limitaciones. Primero: No es posible una medida matemática de los actos y logros educativos que por su naturaleza sean inmesurables. (Cuando reprobaron a Einstein es posible que su calificación haya sido justa en cuanto a los parámetros establecidos, aunque, ciertamente no pudieron medir el potencial inmenso y profundo del genio que iba a revolucionar la orgullosa ciencia de la precisión objetiva). No es legítimo por lo tanto reducirse a apreciaciones numéricas cuando se valoran cualidades y capacidades inconmesurables. Es necesario definir con precisión que lo valuable sea cuantitativamente medible y el criterio de medición. El juicio más sencillo es cuando se juzga lo que se retiene, se recuerda y se entiende. Pero hay que decir que éste no es el elemento más significativo si se pretende valorar avances cualitativos de una educación más integral.

La evaluación deseable creo que debe realizarse en relación al proyecto educativo que se propone. 
Es ciertamente difícil, pero existen algunas luces de acercamiento. E1 Maestro Aristóteles dice en su obra sobre Psicología: "Las potencias se conocen por su actos, la naturaleza de las potencias, por la naturaleza de sus actos..." Por lo tanto, puedo juzgar no matemáticamente pero sí razonablemente cuánto ha crecido la inteligencia por sus ideas, juicios, razonamientos, deducciones e invenciones. Sé de la calidad del entendimiento por la calidad de sus actos. Puedo apreciar el fortalecimiento de la voluntad por la constancia del que siempre asiste, siempre prepara, siempre participa, respeta siempre... Sé que ha aumentado la pasión por la verdad, por la justicia, también por sus actos, por sus entusiasmos, por sus intereses y reclamos. Sé del desarrollo o estancamiento de la responsabilidad social por las actitudes y juicios sobre los problemas sociales...

Ciertamente este campo de evaluación (el más importante) como se ha dicho no puede expresarse en números: suena ridículo un cuatro y no un cinco de calificación a la invención creativa. Sin embargo, el buen maestro lo debe tener en consideración. Por ejemplo, hay que apreciar más un descubrimiento que una buena repetición; se deben considerar mejores los juicios críticos, valorativos, estéticos, morales... que el recital fiel de la memoria; se ha de preferir una expresión de coraje por la corrupción e injusticia a la exacta definición de la virtud de la justicia; se debe apreciar mucho más el servicio social con los marginados que ordenando archivos de las tareas de los profesores.

Pienso, en síntesis, que un buen examen debe constar de tres ámbitos de consideraciones: En el primero, las preguntas sobre lo retenido, recordado y entendido, que esperan respuestas 'objetivas'. En el segundo, evaluación del crecimiento de la inteligencia como razón, como capacidad de argumentar, de demostrar, de unir y desunir, y sobre todo de emitir juicios fundados. $Y$ en el tercero (no el último en importancia), el examen más largo, más vivo, más sutil y substancial, que ausculta, por las participaciones, actitudes y presencia, los otros elementos de la educación del hombre humano: la pasión, la visión elevada, la voluntad hecha carácter, el compromiso social. Y siempre, sin olvidar, que las evaluaciones cuantitativas, los exámenes son un mal menor, y que juzgamos, aunque una mínima porción, pero de un ser humano que nunca podrá ser expresado en números. Finalmente lo que resume todo: el juez indispensable para la mejor valoración posible es el buen maestro con buen 
criterio; lo que yo llamaría, carácter ontológico del magisterio.

Soy consciente de que la visión educativa del hombre humano es ambiciosa, difícil, casi imposible frente a la educación del hombre inhumano producido de acuerdo a exigencias, criterios y valores de una sociedad mecanicista, materialista y mercantilista.

La aspiración a alturas elevadas es muy defendible; como dice Heidegger cuando se refiere al pensar que puede salvar al mundo: "La magnitud de eso que está por pensarse es demasiado grande. Pero construir caminos pequeños no nos lleva lejos. Debemos ponernos a construir el gran paso."

El gran paso, la otra dimensión de la persona, la pasión, la ilusión, la visión, la revolución del pensamiento... constituyen la gran utopía que, como dice Birri, "está en el horizonte, y luego de que camino diez pasos, está diez pasos más allá; camino veinte pasos y está aún más lejos y por más que camino no la alcanzo; pero para eso sirven las utopías: para caminar". Y, por supuesto, para salvarnos de la maldición del fatalismo y de la peste de la desesperanza. 
CITAM Derechos Reservados.

La reproducción total o parcial de este artículo se podrá hacer si el ITAM otorga la autorización previamente por escrito. 